\title{
Proposed Policies for Planning and Managing Water Resources in Egypt in Light of Expected Climate Changes
}

\author{
Heba Nabil Abd Elhamed \\ Lecturer of Environmental Planning, Faculty of Urban and Regional Planning, Cairo University, Giza, Egypt
}

Corresponding Author Email: Eng_Hebanabil@yahoo.com

https://doi.org/10.18280/ijsdp.160617

Received: 4 August 2021

Accepted: 10 October 2021

\section{Keywords:}

climate change, policies, water resources, planning and management, Egypt

\begin{abstract}
Climate change is one of the most serious challenges facing the world and a fundamental challenge to the sustainable development process. Climate change has a tremendous impact on water in Egypt, which is manifested in many pressures on food and water supply, and a direct impact on the economy, politics and society, North Africa has become one of the region's most in need of food preservation with limited water supplies, hence the idea of research working on Achieving the goal to develop policies for planning and managing water resources to ensure Egypt's resistance to the effects of climate change and exposure to water shortage problems, using the Delphi method, which is an organized way to collect the opinions of a selected group of experts and specialists in the field of planning and management of water resources. By conducting a questionnaire to collect the opinions of experts to analyze the water situation The current situation in Egypt and an analysis of the reasons for the quantitative and qualitative deficit in water resources, including it may contribute to the development of a proposal for policies for planning and managing water resources in light of climate changes and measuring the extent of its application in Egypt.
\end{abstract}

\section{INTRODUCTION}

The issue of water scarcity is an increasingly large challenge in the Arab countries, including Egypt, where the Arab region contains the least natural resources of fresh water in the world, and the per capita share is less than 1000 cubic meters of water annually, and as the climate has a major impact on Surface runoff and water availability within the water bodies. Ekwueme and Agunwamba [1] have estimates that climate change will directly affect the flow of water in Arab countries and Egypt, to reduce by $10 \%$ by 2050 , and from here the per capita share of water may decrease annually.

However, in the current situation, Egypt suffers from a shortage of water (demand is much greater than supply), and with the increase in the shares required for individuals to use water, demand is expected to witness a further increase of $60 \%$ by 2045 . Hence, the real problem appears in that we must find proposals for policies and mechanisms that preserve water resources, and find new ways to bridge the expected water deficit in light of the expected climate changes. The research will discuss a set of points such as (clarifying the impact of climate change on the concept of water scarcity and water deficit, clarifying Egypt's position on climate change and its potential impacts on water resources, challenges facing the efficient use of water resources in Egypt (the gap between the current and desirable situation). Studying and analyzing the previous points to suggest policies for planning and managing water resources in light of the expected climate changes and their application in Egypt, achieving the goal of the research paper by discussing a (questionnaire) for a group of experts and specialists in the field of water resources.

\subsection{The research problem}

The main problem of the research indicates that "the expected impact of climate change on water resources and working to understand the potential impacts of climate change has become a necessity to enlighten the way for policies and measure to adapt to these effects in order to avoid reaching dangerous levels of change. Therefore, Egypt should proceed with finding policies to develop planning. Managing the current water resources in light of the future challenges of climate change and identifying mechanisms to activate them in future development (Figure 1).

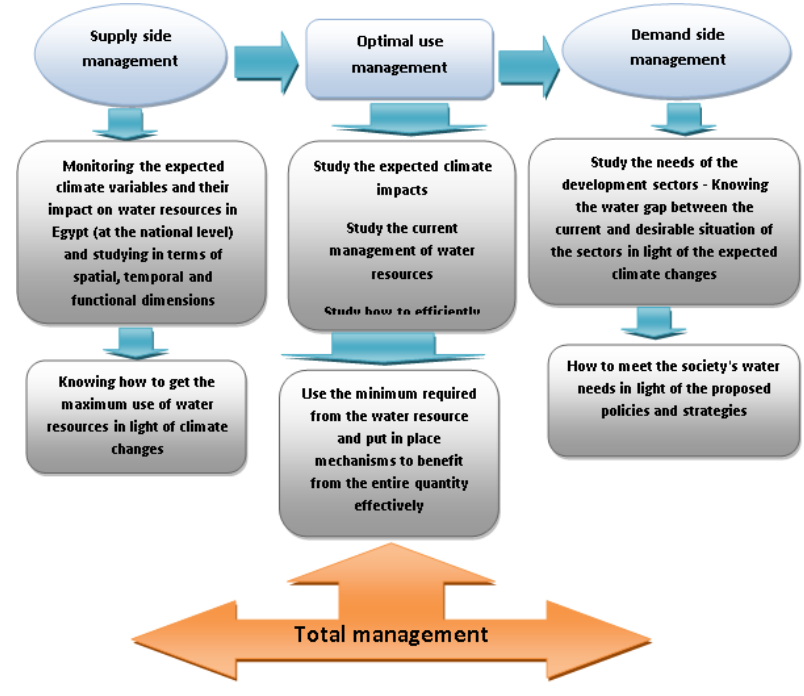

Figure 1. The research problem 


\subsection{The goal of the research}

The research aims to suggest policies for planning and managing water resources and their application in Egypt to avoid the effects of expected climate changes.

\section{THEORETICAL BACKGROUND}

\subsection{The concept of climate change}

The change in the concept that views climate change as an environmental or scientific issue only and climate change has now become a national and global security issue of concern to the whole world. The phenomenon of "climate change" is defined as an imbalance in the usual climatic conditions such as heat, wind and precipitation patterns that characterize every region on Earth, and lead the frequency and magnitude of global climate change in the long term has tremendous impacts on natural biological systems, and leads to widespread and unpredictable environmental, social and economic consequences [2].

\subsubsection{Main definitions of climate change}

The terms used in the field of climate change are numerous in a way that creates a lot of overlap between them, and attempts have been made to separate these terms and define the concept of each of them precisely, whether it is individual attempts or by committees, organizations and international agreements. The most important terms used in the study of climate change are the following:

- A study of the first working group of the International Committee on Climate Change (IPCCWGI). IPCC [3] indicated that the term "climate change refers to the change of the state of the climate and can be detected statistically through the change of the average or the change of climate variability, and this continues for a long period of up to decades or more, and this can result. "A change from internal natural factors, external forces, or continuous human factors, represented by a change in the composition of the atmosphere or the use of the earth".

- The UNFCCC defines climate change as the Framework Convention on Climate Change (UNFCCC). That "refers to climate changes that are directly or indirectly attributable to human factors that change the composition of the global atmosphere, and can be monitored with the natural variations of climate over comparable time periods" [4].

- The second working group of the International Panel on Climate Change presented in its glossary of terms in the fourth report.

"Climate change refers to any change in climate over time, whether due to natural variability or as a result of human activity" [5].

Despite the aforementioned, there is still some ambiguity and overlap between climate terms, especially with regard to what each term refers to from the causes of occurrence or the form and type of this change or the time level of its occurrence.

\subsubsection{Causes of climate change}

The causes of climate change can be divided into two groups:

- Natural causes, including:

a. Volcanic eruptions are emitting greenhouse gases in huge quantities

b. Dust storms in the arid and semi-arid region, which suffer from deterioration of vegetation cover, lack of agriculture and rain.

c. The phenomenon of sunspots, which is a phenomenon that occurs approximately every 11 years due to the disturbance of the magnetic field of the sun, which increases the thermal energy of the radiation emitted from it.

d. The cosmic rays caused by the explosion of some stars hit the Earth's upper atmosphere and lead to the formation of radiocarbon.

- Human causes, including:

a. Gases from various industries, such as oil refining, electric power production, cement production plants, and battery factories.

b. Car exhaust and generators

c. Products of agricultural activities such as fertilizers, fodder, deforestation and trees, which are the largest source of greenhouse gas absorption, especially $\mathrm{CO}_{2}$.

d. The gases emitted from wastewater, especially methane, are ten times more dangerous than $\mathrm{CO}_{2}$.

\subsection{Features of climate change in the Arab world - Egypt}

The Mediterranean region is one of the regions highly vulnerable to climate change in the world and the heart of the tremendous socio-economic transformations of living. Future climate projections have profound implications for the agriculture and water sectors, and the Intergovernmental Panel on Climate Change (IPCC). Temperatures in the Middle East will increase by two degrees [6]. Two percent in the next 1520 years, at a rate of more than 4 degrees Celsius at the end of this century, and you acknowledge that climate change will increase the stress on water availability for society and the natural environment in Africa.

\subsubsection{Features of climate change in Egypt}

Egypt is characterized by a semi-desert climate (hot, dry summer and mild winter accompanied by little rain and winds blowing in some areas overlooking the Egyptian shores). Egypt is also distinguished by its location on the Mediterranean Sea to the north and the Red Sea to the east. The Egyptian beaches extend about $3500 \mathrm{~km}$ and include features of climate change in Egypt. Change in rates of both temperature and precipitation [7].

- The rate of change in temperature:( Figure 2)

Some studies indicated that the annual rate of change in temperature in Egypt reached $0.11^{\circ} \mathrm{C}$, where the temperature decreases at a rate of $0.1^{\circ} \mathrm{C}$ per decade in the Delta and Cairo region, and decreases between 0.05 to $0.07^{\circ} \mathrm{C}$ per decade on the shores of the Mediterranean, the Red Sea and Central Egypt, As for Upper Egypt and Western Sahara, the average temperature rise ranges from 0.22 to 0.32 degrees Celsius per decade.

- Annual rate of change of precipitation:

Rainfall in Egypt is very low, erratic and unpredictable. The average annual precipitation ranges from a maximum of 200 $\mathrm{mm}$ in the northern coastal region to no less than zero in the south, with an annual average of $51 \mathrm{~mm}$ (Figure 3). Similar to the temperature, monsoon precipitation is expected to change including timing, intensity and shape of rain. Precipitation differs from temperature in that it has greater spatial variability and is difficult to predict [8]. And changes in precipitation and 
temperature interact. Higher temperatures increase evaporation, which may lead to a drier climate.

The annual rate of change of precipitation in Egypt is about $11.4 \%$ per decade, and this rate ranges between $0.86 \%$ and $49 \%$ per decade for different regions, and for the winter and spring seasons, the rate of rainfall increases for all regions

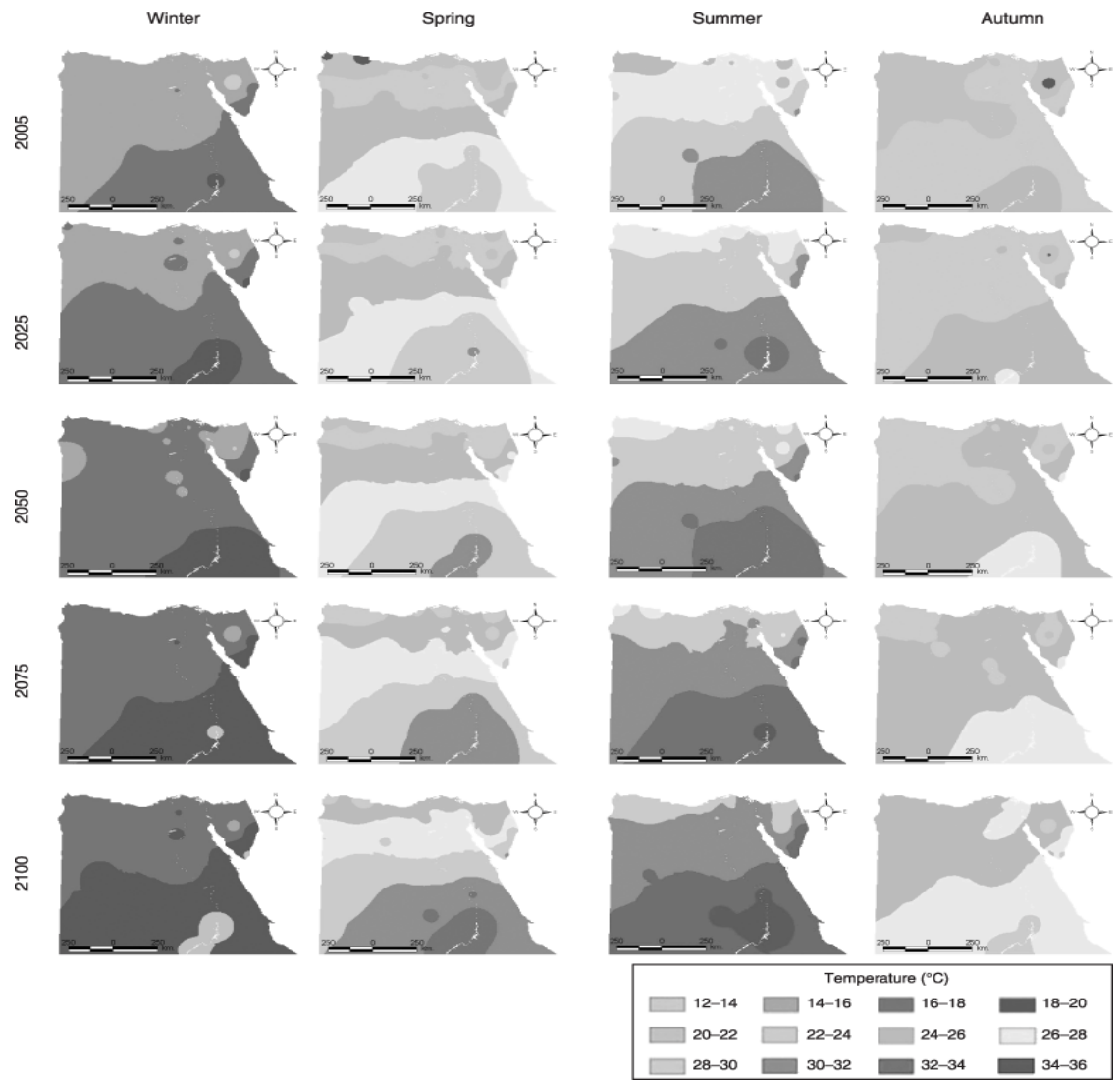

Figure 2. Seasonal air temperature distribution in Egypt during the year 2005 and in the projected years 2025,2075 and 2100 [9]

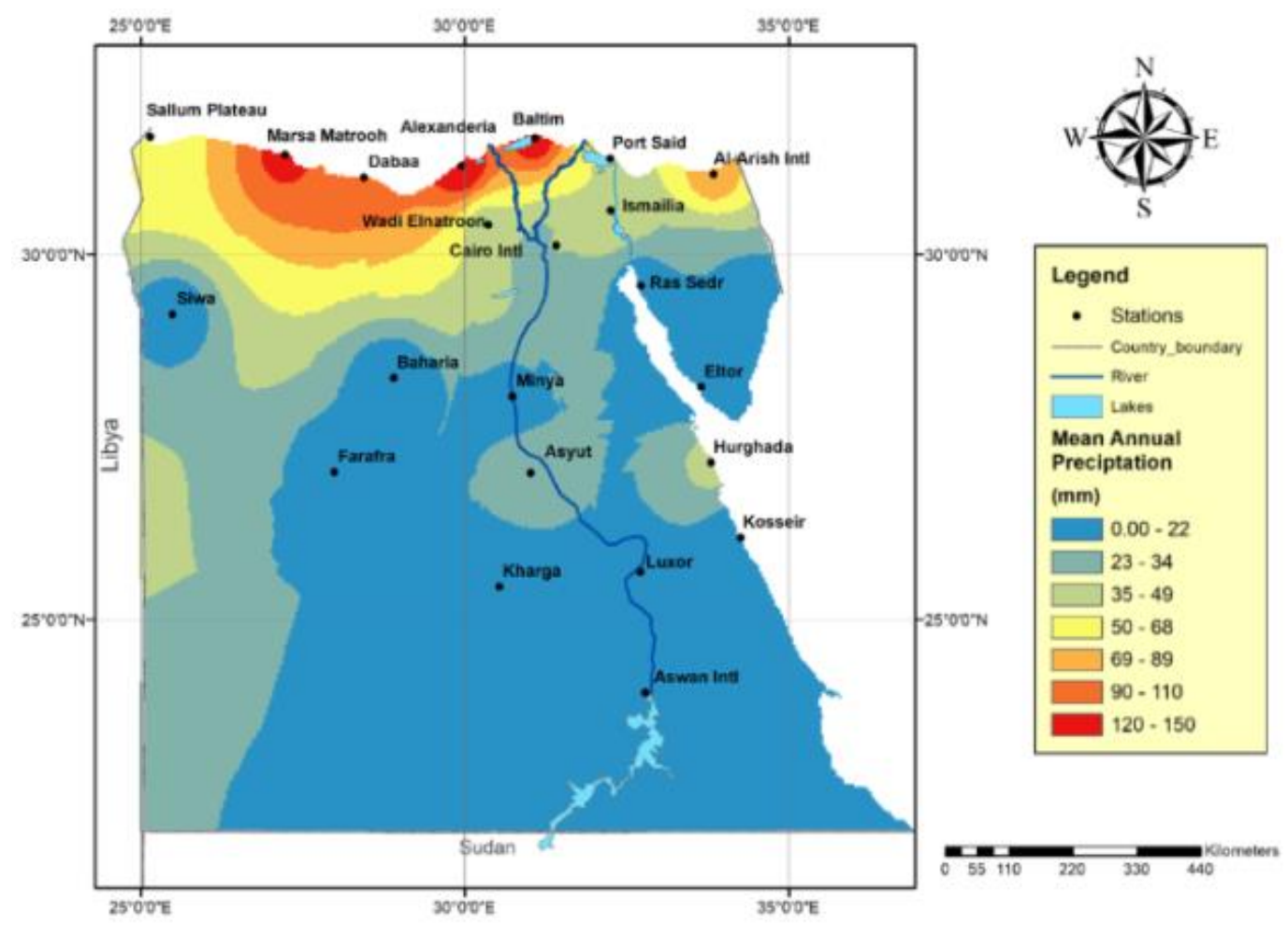

Figure 3. Annual rainfall in Egypt for the period 1957-2017 [10] 


\subsection{The concept of water resources}

\subsubsection{Water resources and their scarcity}

Water is one of the most important natural resources on which human life depends and all urban, social and economic activities in various fields, especially in the field of agriculture and industry. Water is characterized by the fact that its quantity is constant in the globe and is constantly renewed during a specific period of time thanks to the hydrological cycle. Studies of the water balance on the surface of the Earth have concluded that the water resource in general may be scarce as a result of exceeding demand and misuse of water in the foreseeable future [11].

Arab countries will face a large deficit in the future in water resources if the current situation continues and without taking into account the potential effects of global climate changes. Figure 4 shows water scarcity in the Arab world 2025 Climate models predict a hotter, drier and less predictable climate, resulting in a $20 \%$ to $30 \%$ decrease in water surplus across most of the MENA region by 2050, mainly due to higher temperatures and less precipitation [12]. The latest World Bank report, "Turn down the Heat: Confronting the New Climate Normal," predicts that a significant increase in heat waves combined with average warming will put intense pressure on already scarce water resources, with dire consequences for human consumption and regional food security. In Jordan, Egypt and Libya, agricultural yields could decline by up to 30 percent with a warming of around 1.5 to 2 degrees Celsius by 2050, and migration and climate-related resource pressure could also increase the risks of conflict (Figure 5).

\subsubsection{Challenges facing the efficient use of water resources in} Egypt

There are six main challenges facing water use efficiency in Egypt, which are as follows: The first and most important challenge is the growing population and the associated increase in demand for water on public water supplies and economic activities, especially agriculture (the population increased from 38 million in 1977 to 63 million in 2000, and to about 84 million in 2012, and is expected to reach 104 million in 2025, and to 237 million in 2100, the second challenge is to reduce the expected flow of the Nile, which appeared recently due to the rapid implementation plans of the Ethiopian dams, which represent a serious direct and immediate threat to the needs of Egyptians essential water.

The third challenge stems from the projected impacts of climate change on the Nile flows and the different demands of the water sector.

The fourth challenge is the quality of water in the canals network due to interaction with domestic, industrial and agricultural activities to increase the population, especially in the Nile Delta.

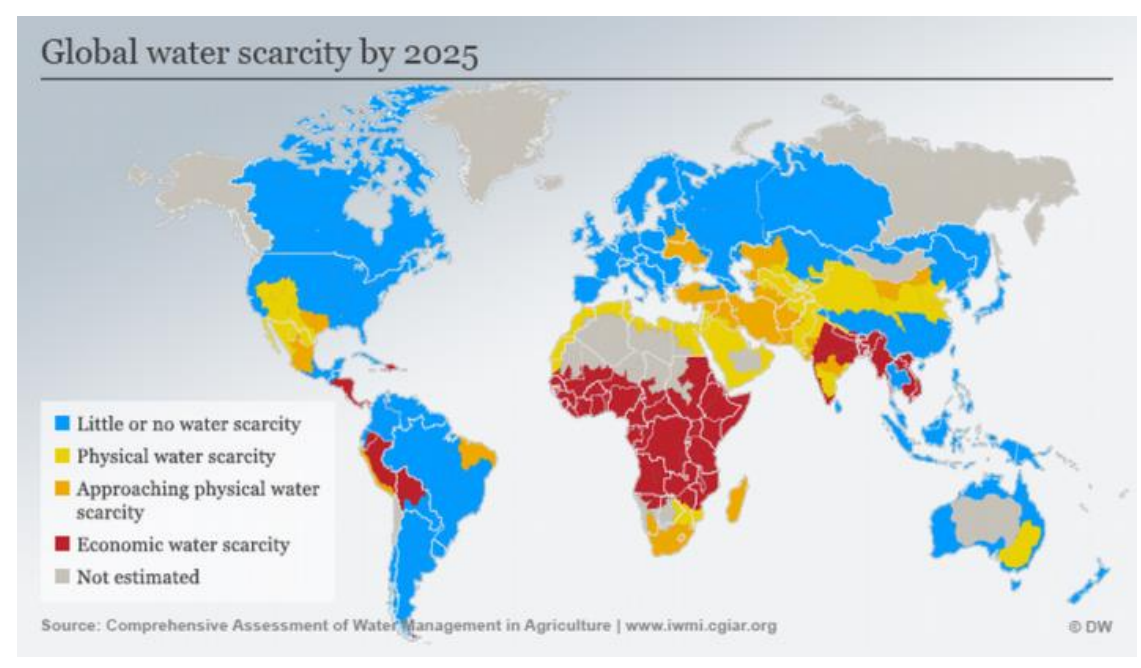

Figure 4. World Water Scarcity 2025 [13]

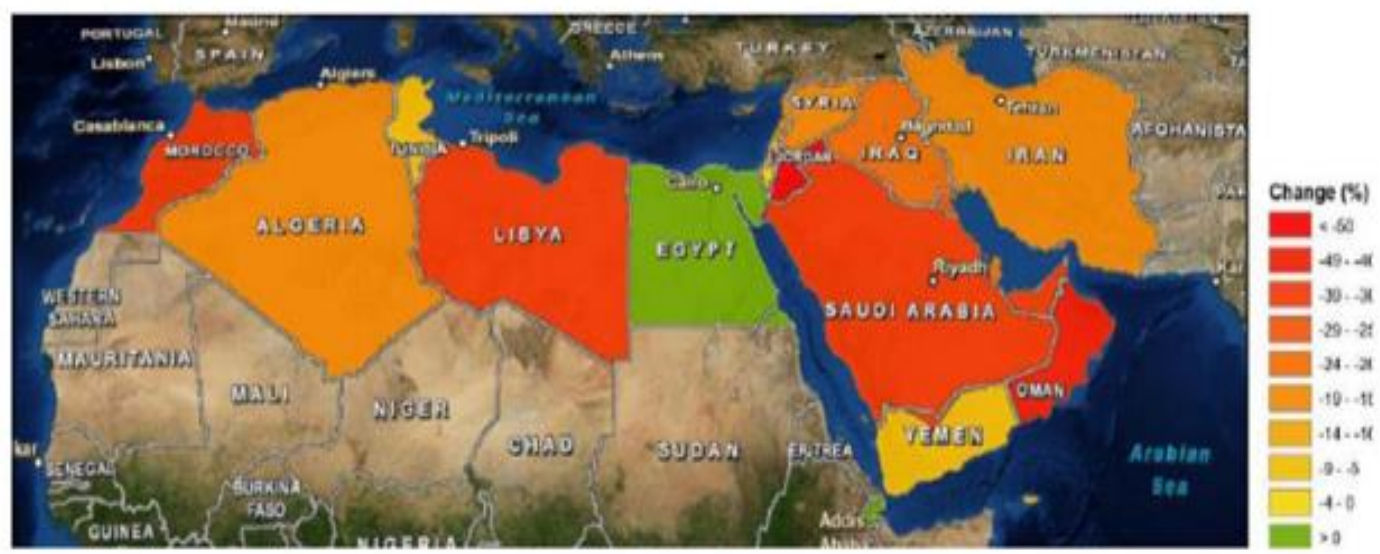

Figure 5. Features of change in water resources in the Arab world 2010-2050 [14] 
The fifth challenge is the institutional setup for water management, which is both governmental and pivotal in nature. The management of the water sector must be efficient and able to handle the recent rapid expected changes.

And finally, the sixth challenge is the sea level rise that threatens coastal areas and the Nile Delta in particular, where a large area is exposed to flooding and also affects the quality of fresh coastal aquifers due to seawater intrusion.

\subsection{Potential impacts of climate change on water resources in the Arab world - Egypt}

The expected climate changes in the Arab world - Egypt have a direct impact on water resources affecting all human activities, and the impact is represented in many problems as follows:

\subsubsection{Increasing the water needs of agricultural crops}

Rising temperatures will lead to an increase in the water requirements of plants, which will increase the demand for water resources and decrease crop productivity, which threatens food security.

\subsubsection{Lack of recharge for groundwater aquifers}

Studies [15] indicated that the recharge of groundwater reservoirs will decrease by about (30 to $70 \%$ ) in the southern and eastern regions of the Mediterranean Sea as a result of decreased precipitation, higher temperatures and increased evaporation rates from the unsaturated range as it is. Explained in Figure 6.

2.4.3 Increase the frequency of drought cycles in mediumaltitude and semi-arid low-lying area

The possibility of increasing the recurrence of the phenomenon of drought in the Arab world as a result of climate change is of concern because of the great impact of this phenomenon on food security and economic growth.

\subsubsection{Sea level rise}

The rapid melting of the ice sheets as a result of high temperatures can lead to a rise in sea level, as it is expected that the sea level will raise by $20-50 \mathrm{~cm}$ according to the central scenario of temperature change (1.7-2.4) degrees Celsius [16], as shown in Figure 7. Such a rise according to the report of the United Nations Program [17] led to the inundation of large areas of coastal areas, the decrease in the volume of usable fresh groundwater, the formation of new marsh areas in the depressions near the coastal line of the sea, the deterioration of agricultural drainage systems and the necessity to use pumps to raise water to the sea.
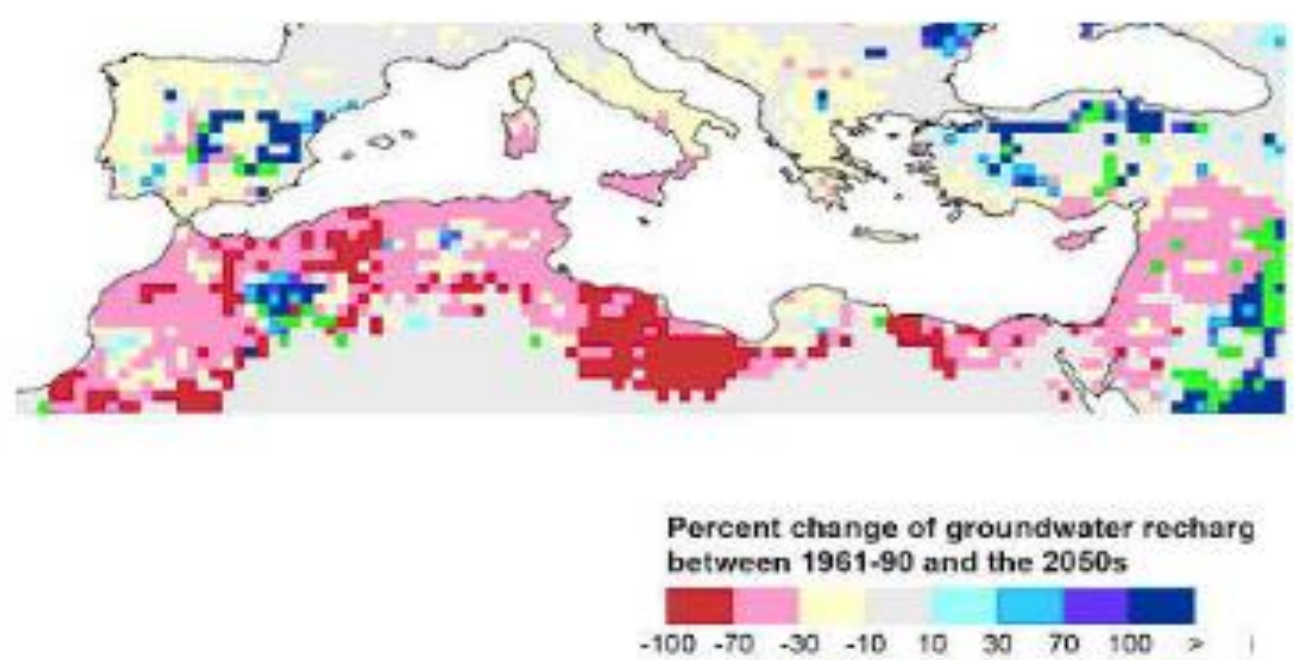

Figure 6. The change in groundwater recharge between (1961-1990) and 2050 [15]

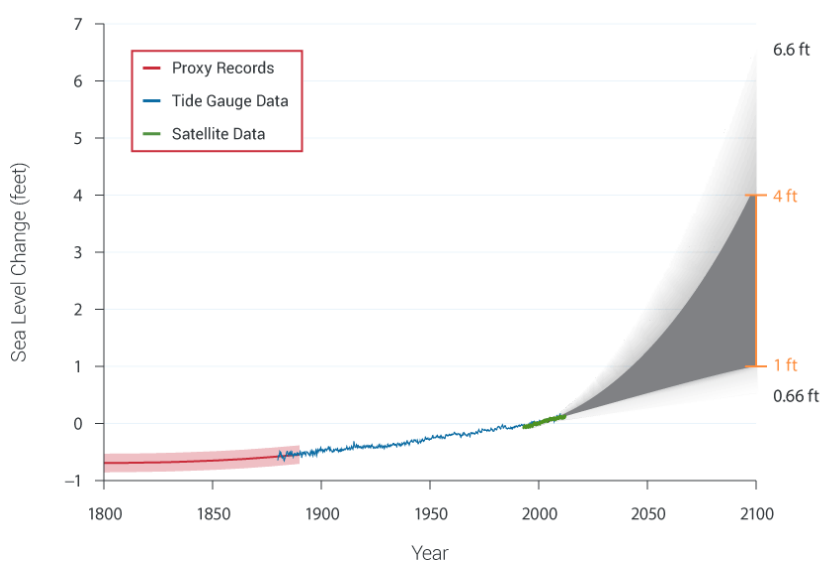

Figure 7. Sea level rise due to climate change [18]

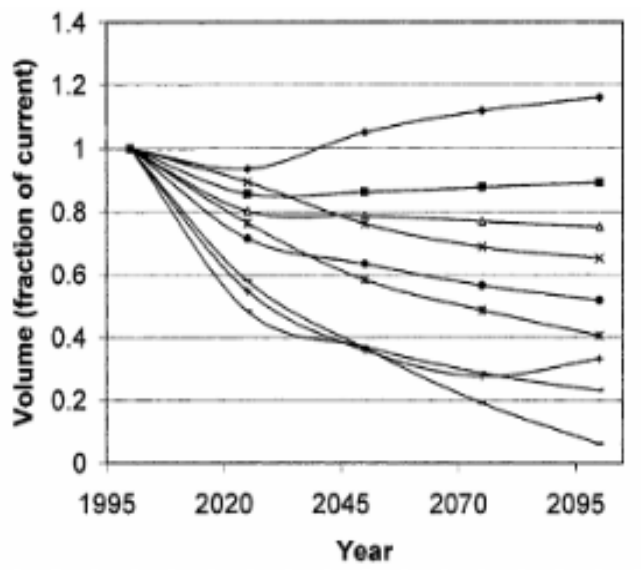

Figure 8. Change in the flow of the Nile water [19] 
2.4.5 Reduced river discharge and the amount of surface runoff

According to the IPCC 2007 report [16], the springs of rivers that flow or emanate from the Arab world, especially in the south and east of the Mediterranean basin, will experience a decrease in their water balance within the limits (10 to 20\%), and the change in rainfall and temperatures will lead to an increase in the amount of surface runoff by $10 \%$. $-40 \%$ in highland areas and low tropics, but in dry areas, the amount of surface runoff will decrease by $10-30 \%$ as a result of the decrease in the amount of rain and the increase in the rate of evaporation.

\subsection{Potential impacts of climate change on water resources in Egypt}

In Egypt, there has been an increase in the severity of warnings of the possibility that climate changes, which are beginning to emerge, lead to serious environmental disasters such as droughts, represented by episodes of long absence or marked decrease in precipitation rates. Rivers flowed at a rate sufficient to meet water demand and consumption.

The Nile River is the main source of Egypt's water, as it represents more than $95 \%$ of the water resources ( 55.5 billion cubic meters), while the rain on the northern coast and ground water represents $5 \%$ - and agriculture consumes about $80 \%$ of the water sources, while industry and human use consume $20 \%$ (and it represents the rainfall on the hills of Abyssinia is $85 \%$, while the rains in tropical lakes represent $15 \%$ of the Nile water resources [20, 21].

Egypt faces a double problem, as the supply of fresh water from south to north will decrease as a result of the drought that will afflict the countries of the headwaters of the Nile due to the high temperature, while the waters of the Mediterranean Sea will invade the northern part of the Nile Delta and move towards the south of the delta due to the rise in sea level. The majority of studies conducted on the national and global scale, which took into account the effects of climate change on the flow of rivers, indicate that water stress may increase with climate change in Egypt, as these studies indicate that the flow of the Nile water may decrease significantly with climate change. Evaporation in tropical and subtropical areas will decrease the amount of Nile River water, and consequently the shares of the beneficiary countries will decrease, which diminishes the development opportunities in arid and semiarid countries, although the impact of climate change on the sources of the Nile is still uncertain and ranges from an increase in The amount of rain is accompanied by floods in Abyssinia, Sudan and Egypt, followed by a period of drought, or a decrease in the amount of rain with an increase in the rate of evaporation. However, the likely scenario is an increase in evaporation rates with a constant the amount of rain comes on the plateaus of Abyssinia, as mentioned earlier, which constitute about $85 \%$ of the Nile water sources.

Some studies, which relied on mathematical models to draw nine scenarios that represent a full range of the impact of climate changes on the Nile River, indicate a decrease in Nile water flows until 2040, while only one scenario predicts an increase in the rate of Nile water flow after 2045 as shown Figure 8.

With the increase in evaporation rates, Egypt's share of the Nile water decreases, especially since a sizeable part, which represents about $20 \%$ of the prescribed share for Egypt, is dispersed in the lands of southern Sudan before the Nile enters
Egypt - due to the large branches and the narrowing of the original stream. It is estimated at about $70 \%$ in the year 2050 or a little later, and then the increase in the demand for water for agricultural and industrial purposes - this means a decrease in the per capita share of water by more than $66 \%$ in the year $2100 \mathrm{AD}$, knowing that $95 \%$ of the natural water that feeds Egypt comes From the Nile River.

By interacting with the scenarios developed by climate scientists, global warming in Egypt will accelerate the evaporation of the Nile water and thus reduce fresh water resources, which in turn will exacerbate the country's severe shortage of drinking water, irrigation, and electric power generation. The scenario has dire social and economic consequences, one of which is Egypt's inability to feed its people, which now number around 100 million.

It is expected that all water resources and demand will be negatively affected with climate change as follows:

- The increase in temperature will lead to an increase in evaporation and an increase in the quantities needed by agriculture and domestic and industrial consumption.

- The change in rainfall patterns will lead to water shortage in coastal areas.

- The increase in water levels and the increase in salinity in the soil lead to a deterioration of the water quality.

- Rising sea levels will increase the penetration of salinity under the soil and lead to pollution of groundwater sources in coastal areas.

As the change in rainfall, wind speed and extreme heat waves leads to:

- Increasing the exposure of informal areas to the dangers of wind and flood and increasing the exposure of rural and some urban areas to a high rate of floods and fires. The human settlements that were built in the depths of ancient torrents are among the most affected areas.

- Increased vulnerability to livestock as a result of water shortages, increased soil salinity, high air temperature, and the disappearance of areas of grazing land.

- The change in the number, times and duration of extreme heat waves negatively affects agricultural production and increases the number and types of agricultural pests.

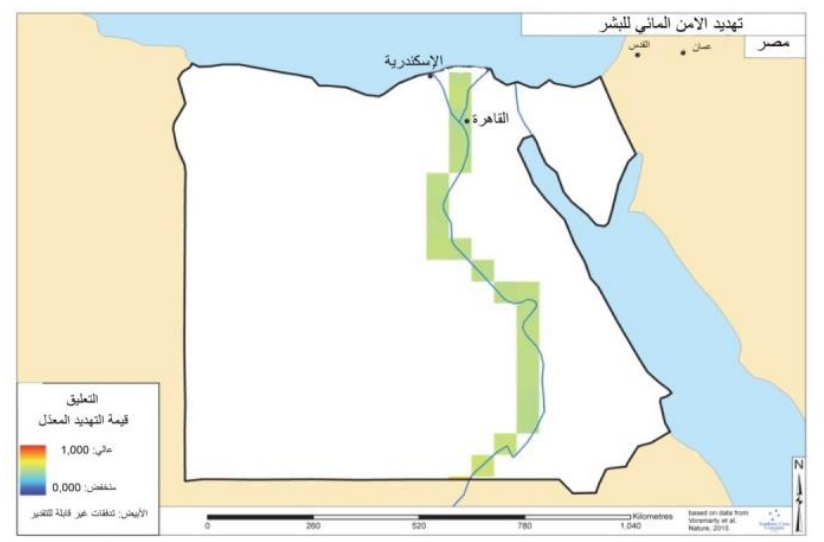

Figure 9. Egypt's current modified Water Security (HWS) threat [22]

The Figure 9 shows the level of threat to human water security in Egypt - (This index is a function of the cumulative effects of 23 biophysical and chemical drivers that have been 
globally scaled to produce an average indicative of the current threat to water security for humans.) Which ranges from medium to low, with the dominance of the use of surface water through the Nile River in Egypt, 97.6\% of the total renewable water resources in Egypt come from surface water, while 2.4\% is derived from recharge of groundwater [23]. And shows the occurrence of the inhabited area and activities along the Nile Valley in the average value of the rate of threat to human water security, which ranges from 0.00 as a low value to 1.0 as a high value.

Here, the Figure 9 shows that at the level of surface water represented in Egypt in the Nile River, there is a water threat and deficit now and in the future.

\subsection{Water resources planning and management}

2.6.1 The concept of planning and managing water resources The planning and management of water resources is a variable definition according to the society and the state of the environment and the site of the study, as the management processes may agree from one country to another according to the state policy, the water resources in it and the available technologies, and it is defined as "the process that encourages the development and coordinated management of water, land and related resources for the sake of "Achieving the highest levels of economic and social well-being, resulting in an equitable manner without compromising the sustainability of vital ecosystems" [24].

Integrated water resource management is a specific application of the more general theory of integrated environmental management that aspires to deal with the natural environment. Integrated environmental management can be considered as a set of standards related to preserving the environment in the presence of many diverse uses and activities [25].

\section{PROPOSED POLICIES FOR PLANNING AND MANAGING WATER RESOURCES IN EGYPT IN LIGHT OF CLIMATE CHANGES}

\subsection{Field work}

In order to arrive at the proposed policies for planning and managing water resources in Egypt in light of climate changes, a field study was conducted by conducting interviews with experts concerned in the field of research from academic experts, consultants, research centers, government representatives and thinkers.

This interview aims to discuss the causes of the quantitative and qualitative deficit in water resources and the possibility of creating new resources in the future to bridge the deficit in addition to methods for including the dimension (temporal, spatial and functional) in planning and managing water resources in light of climate changes and concluding a method for measuring the efficiency of planning and managing water resources in terms of The quantity and quality to obtain the maximum benefit from the water resources currently, as well as the institutional and legislative framework that can support efficient management, and the experts' suggestion of the most successful global experiences in the field of water resources management, and the possibility of creating an efficient management model that can be applied to Egypt.

Also, this part includes analyzing previous data collected in the theoretical study of research and field work and analyzing the final results of expert questionnaires in order to facilitate the process of reaching results and recommendations to achieve the research objectives.

The Delphi method was used in the research, and it is an organized means of communication between a selected group of experts and specialists in a specific field (planning and management of water resources) to answer questions by making a questionnaire form to collect expert opinions to arrive to analyze the current water situation in Egypt and analyze the causes of quantitative deficit. And the qualitative nature of the water resource and the focus on concluding policies for the efficient management of water resources in light of climate changes, by suggesting experts for international experiences in the field of water resources and measuring the possibility of its application to the Egyptian urbanization.

In the standard Delphi method, experts answer questionnaires related to the topic to be explored in two or more rounds. After each round, a mediator sends an anonymous summary containing a summary of the experts' expectations from the previous round and the reasons on which their judgments are based. Consequently, experts are encouraged to review their previous responses in light of responses from other members of the expert committee. It is believed that during this process the range of answers will be narrowed and the opinions of the expert group will converge towards the "correct" answer.

3.1.1 Design the questionnaire form for the experts concerned

The questionnaire was designed according to the research objectives on each of the research elements, and when designing it, the following was taken into account:

- The questions are easy.

- No compound questions.

- The answer is yes, no, or I don't know.

- Repeating some questions in more than one format to get an accurate answer.

- There are some open questions to get an extensive answer to the opinion of the experts to limit all the information to the experts.

- The questions were divided into groups according to the research objectives.

\subsubsection{Basis for determining the study sample}

The sample was chosen so that it reflects the opinions of the parties concerned and is mostly based mainly on academic experts (Faculties of Agriculture,25 person-Science and Engineering at Cairo University, 30 person - Soil, Water and Environment Research Institute, 30 person - National Center for Water Research in Al-Qanatir Al-Khayriya , 15 person) by $65 \%$ of the sample. The questionnaire needs scientific answers from academic experts in the field of water to cover questions related to the concepts of water resources management and the dimensions (time - place - function) to it, methods of obtaining the most benefit from water resources currently, the potential impacts of climate changes, and suggesting and analyzing experts' proposals to reach policies for planning and managing water resources in Egypt.

Then the executive experts (the Holding Company for Drinking Water and Sanitation - Irrigation Authority Ministry of Housing) with $35 \%$ of the experts to cover the part of the current and expected water resources potentials, the 
causes of water deficit, and the analysis of the current management system for water resources in Egypt.

3.1.3 Questionnaire analysis results - an appendix to the questionnaire form

At this stage, the questionnaire forms were collected and analyzed at the level of each group of stakeholders (academic experts - executive experts) and at the sample level, all of them were quantitative and descriptive analysis, as shown in the following:

- Amount of water resources available in Egypt

- $73 \%$ of a specialized expert and $95 \%$ of an academic expert agreed that Egypt's share of the Nile water would be fixed at 55.5 billion cubic meters, and $27 \%$ of the experts did not answer this question. The question indicates that the executive authority does not have clear data on the amount of water resources in Egypt, and this is one of the reasons for poor planning and management (Figure 10).

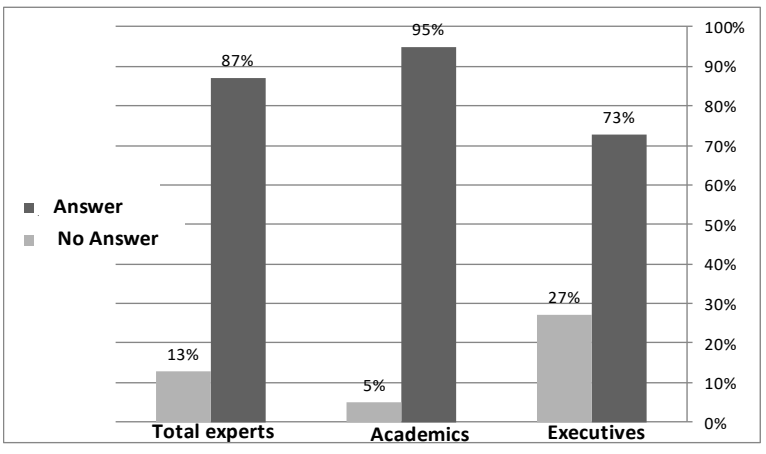

Figure 10. The answer to the amount of water resources

- The adequacy of the current water resources for the needs in Egypt:

- $64 \%$ of the executive experts answered yes that the current amount of water resources is not sufficient, and $36 \%$ said yes, it is sufficient as the annual amount of water resources in Egypt is many, but as a result of waste, it does not reach the consumers and this is mismanagement. As for academic experts, 95\% of them they answered that it is not enough. The current amount of water resources is the needs in Egypt, and only $5 \%$ of the experts answered yes, it is enough (Figure 11).

- The deficit in water resources in Egypt in light of climate changes: (Figure 12).

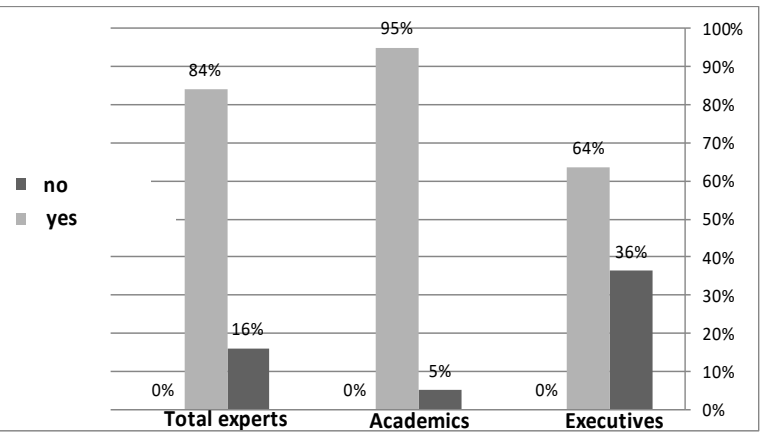

Figure 11. The answer to the adequacy of the current water resources for the needs in Egypt

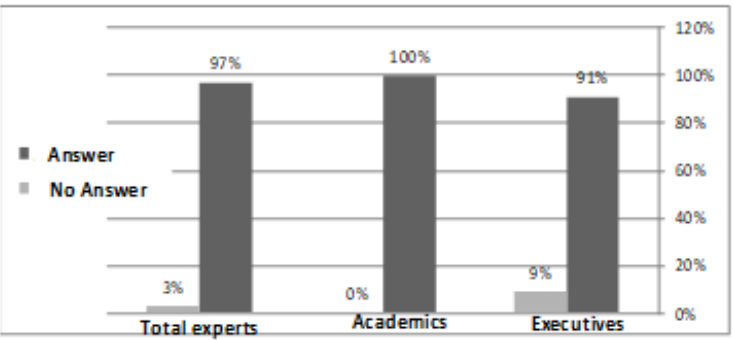

Figure 12. The answer to the deficit in water resources in Egypt in light of climate changes

- $91 \%$ of the experts answered the causes of the current deficit, which are the lack of good planning and good management of water resources in Egypt, and poor distribution - lack of awareness of rationalization of consumption, misuse and wrong behavior of citizens an increase in population with the amount of proven water resources since 1959, an increase in the percentage of waste in Networks where there is no preventive maintenance of the networks - the use of traditional methods and old techniques in irrigation and agriculture - the depletion of drinking water networks and thus the increase in the percentage of water losses - the lack of maintenance of channels and drainage networks - the Renaissance Dam and the consequent shortage of Egypt's share of water - limited resources Available water, and academic experts added 100\% about the causes of the current deficit, which is the increase in water demand, including (population increase - agricultural expansion projects outside the valley - climate change - leakage and evaporation rate - dams and water projects on the Nile Basin) in contrast, the unconscious consumer culture Among citizens failure to activate the integrated management system for people - water response - lack of water awareness low efficiency of water use - lack of effective means Water resources management - lack of a water management system - lack of clear pricing water policy - wasteful use of irrigation water as $85 \%$ of total water resources in general are directed to agriculture excessive use of water for domestic use - bad relations between Nile Basin countries - poor Surface and groundwater management - lack of relationship between management, water and housing agencies lack of law to punish violators of water use - volatile change with technological advances - external obstacles affecting the current lack of availability neglect of expansion in areas with untapped water resources - neglect of water reuse policy That was previously exploited - stabilization of the water share of the Nile River - lack of capabilities and energy needed to desalinate sea water - most of the water resources come from outside the country and there is no control. They and the Nile Basin countries have to control the behavior of the branches feeding the Nile severe pollution of the Nile water - cultivation of desert areas without covering the water deficit (expansion) weakness of institutions that manage the water that causes waste - water distribution networks are very poor and cause many water losses - climate changes It leads to increased evaporation, increased water consumption of cultivated crops - reduced rainfall - 
some private policies such as continued cultivation of rice and sugar cane.

- Experts have indicated that the deficit ranges between 40:10 billion $\mathrm{m}^{3}$, and that water resources can be developed in the future (expanding the use of groundwater wells - treating sewage water in a way that allows it to be used in irrigation and industrial purposes according to industry types - agricultural drainage water. Mixed with irrigation water in some proportions according to the percentage of salinity that the crop can bear - desalination of sea water - national water conservation projects - rainwater, fog and fog harvesting, and the use of small dams to benefit from flood water - Implementation of joint projects with the Nile Basin countries - Renewable groundwater - Reuse of agricultural and sewage water - Desalination of sea water - Deep groundwater within safe clouds Rationalization of irrigation water in agriculture Preservation of losses in the dam area in Sudan (Jonglei Canal) and collecting them in a channel to extend the Nile River - Interest in research on rainfall - The use of crops that attract water vapor - Desalination of sea water - - The technique of using dew water).

- The amount of water resources required to meet the current needs:

- $55 \%$ of the experts did not answer and only $45 \%$ answered, and the answer varied from 10 billion $\mathrm{m}^{3}$ to 100 billion $\mathrm{m}^{3}$, and this indicates the lack of clear data on the water needs of the executive authority, and they are the ones responsible for the water management process in Egypt. Academic experts, $10 \%$ of them did not answer, and $90 \%$ answered, and the answer varied from 20 billion $\mathrm{m}^{3}$ to 100 billion $\mathrm{m}^{3}$ to take into account future expansions, so that the share of one citizen is not less than $1000 \mathrm{~m}^{3}$ / year, and this indicates that academics have no clear data on water needs (Figure 13).

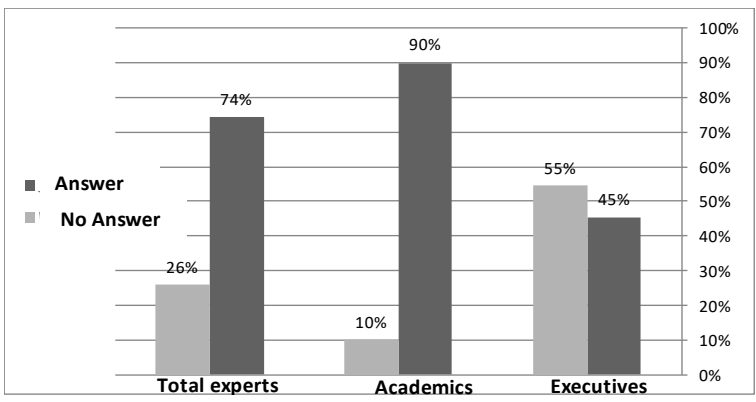

Figure 13. The answer to the amount of water resources required to meet the current needs

- Concept for managing water resources - legally temporally - spatially:

- $73 \%$ of experts answered the definition of water resources management as the optimal use of water resources, preserving it from waste and pollution, developing it, trying to increase it, and trying to achieve a balance between the need for water and available water and its fair distribution in light of the sustainable development of the resource. The problem should be determined in advance based on accurate information. It is submitted to the executive authorities in light of the laws and regulations governing this.

- $73 \%$ of the experts agreed that there is no legal concept of water resources management, and this indicates the necessity to include the concepts of water resources management in laws and legislation. As for academic experts, $45 \%$ agreed that there is no legal concept of water management. Water resources. By reviewing the laws, it was found that there is no concept of water resources management in them. This indicates the need to incorporate the concepts of water resources management into laws and legislation.

- Not taking into account the time dimension when exploiting water resources in Egypt now: $46 \%$ of the executive experts answered yes, as the time dimension is taken into account when exploiting water resources in Egypt, and this is unanimously, as is the case for the rest of Egyptians, while academic experts answered $55 \%$ Yes, the time dimension is taken into consideration when exploiting water resources.

- Not taking into account the spatial dimension when exploiting water resources in Egypt currently, 18\% of the executive experts answered yes, and the spatial dimension is taken into account and this is a very small percentage and indicates the lack of awareness of the executives about the developmental dimensions and linking resource management with the spatial dimension, while the experts answered Academics, $55 \%$ of them yes, and that the spatial dimension is not taken into account, as most development projects depend on transported water and not according to the resources available in the place.

- Existence of an existing system for planning and managing water resources in Egypt: (Figure 14).

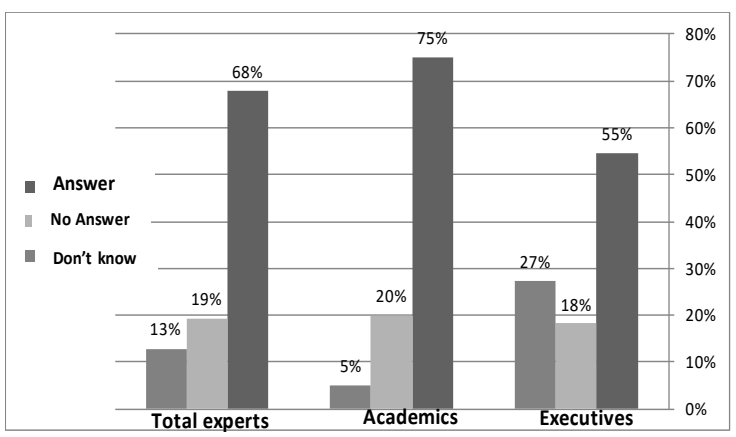

Figure 14. The answer to Existence of an existing system for planning and managing water resources in Egypt

- $55 \%$ of the executive experts answered yes. There is a water resources management system in Egypt, but only $27 \%$ of those who recommended to refer to the Ministry of Water Resources to know the components of this system and this indicates the lack of awareness of the executive authority of the water resources management system and this is considered a deficiency in the administration as they are responsible About water resources management in addition to $27 \%$ did not know whether there is a current system and $18 \%$ did not answer no that there is no system for water resources management currently in Egypt. As for academic experts, $75 \%$ of them said yes. There is a water resources management system in Egypt and they recommended referring to The National Plan for Water 
Resources Management in Egypt 2017 at the Ministry and they clarified that the elements of the current system (estimating needs - calculating what is needed from the dam according to the time dimension monitoring the quantities spent for each part (administration - center - canal) - maintenance of networks and control facilities) and that the management is currently being done At the level of production facilities and not at the level of regions in a planning way.

- How to manage water resources with the integration of dimensions (time, place, and function) in light of potential climate changes:

- Only $27 \%$ of the executive experts answered and focused on institutions to create integration between sectors by activating the Higher Coordination Committee for Water Management headed by the Ministry of Irrigation and Water Resources and all relevant ministries and the existence of coordination between the Ministry of Irrigation and Agriculture to determine the periods of overuse to provide water within a river The Nile and how to reuse water in Egypt and cooperation between sectors to create an integrated national plan. As for academic experts, $80 \%$ of them answered that water resources can be managed by integration between dimensions (time, place, and function) by generalizing the concept of integrated water resources management and work. On its sustainability - implementing the water governance system and adding the economic and social dimension - coordination between the relevant parties such as the various ministries, the most important of which is the Ministry of Irrigation, Housing, Industry and Agriculture, in order to meet the needs in time, place and quality as much as possible - Developing a cooperation plan at the national level with the help of experts in various Specializations - That the water resources are used in the best places for agriculture in Egypt (places where water consumption is the least possible, such as the North Coast and East And West Delta) and $20 \%$ of the experts did not answer.

- Policies for utilizing water resources in the presence of climate change:

- $64 \%$ of the executive experts answered that it is possible to obtain the maximum benefit from water resources by rationalizing consumption - reducing water losses - taking into account the economic dimension - organizing the agricultural cycle - reducing heavy crops to water - reducing water pollution exploiting non-water sources Traditional (Arish Valley has 5 billion cubic meters of water that is not used) Conducting awareness campaigns for farmers and citizens - Activating the Qattara depression project for academic experts, $85 \%$ answered and their answers are close to each other that it is possible to get the most benefit from water resources by raising the efficiency and maintenance And the development of water transmission and distribution networks - raising the efficiency of surface irrigation - changing the composition of crops - developing irrigation systems rationalizing the use of irrigation water - generalizing the concept of water as an economic commodity generalizing the concept of virtual water to decision makers - integrated management of land and water to achieve sustainable agricultural development updating Needs Guide for hydroponics in agriculture and irrigation scheduling - activating punishment and reward laws - reviewing different water priorities consuming sectors - restoring Thinking about food security standards and using principles of virtual waterbased management - using modern irrigation systems dealing with water resources on an economic basis (achieving the greatest benefit) - not reclaiming land using non-renewable water resources and can be used in industry instead - using water Appropriate use of water quality - Restoring the agricultural cycle of crops - Recycling and treatment of sanitation for non-food crops - Cooperation between all sectors that use water to determine the actual needs of each sector and raising the efficiency of using the water unit in each sector separately - Using modern programs for water management - taking into account The temporal and spatial dimension - societal awareness - water reuse, agricultural, sanitary and industrial drainage. $15 \%$ of the experts did not answer.

- The foundations that can be applied in Egypt to reach the optimal water situation, only $27 \%$ of the executive experts answered that they focused on modern technology in water management and treatment and educating citizens, and that citizens are aware of the issue of water shortage and good planning to solve the problem and rationalize consumption - Coordination with the responsible authorities On water pollution application of the offending law - sea water desalination - scientific research - less water use.

\subsection{The proposed policies for planning and managing water resources in Egypt in the presence of climate changes}

The quantitative analysis of the research is reflected in the proposed policy proposal through the group of experts and the questionnaire. Detailed policies have been proposed according to each sector according to the proposals at all development levels.

A proposed model for planning and managing water resources and solving the water problem in Egypt in an effective and objective manner in the presence of future climate changes includes the following:

- Inclusion of the concept of planning, management and efficiency of water resources in Egyptian laws and legislations.

- Update the data related to the quantities of water resources in the Ministry of Water Resources and add the actual use of water and accounts for the quantities of losses.

- Establishing a unified law for water resources and conducting training courses for water-related institutions to become familiar with the laws governing water works.

- Protecting Egypt's common water rights with neighboring countries by activating international agreements, such as the Egypt and Sudan Agreement, to benefit from the waters of the Nile.

- Maximizing the utilization of water resources and protecting them from wastage by developing mechanisms for sustainable planning and management.

- Mainstream dealing with water resources through dimensions (time - place - function) and their 
integration.

- Creating unconventional water resources to fill current and future deficits.

- The inclusion of mechanisms for measuring water efficiency in the development sectors in the implementing regulations.

- Transparency in dealing with the water problem in Egypt and the issue of the Renaissance Dam.

- Coordination and interdependence between the various bodies concerned with water in Egypt.

- Eliminate administrative corruption that exists in institutions related to planning and managing water resources.

- Information linkage between the parties involved in water resources management in Egypt to speed up the process of information transfer.

- Involving the beneficiaries in the water management process, through water user associations.

- Conducting awareness programs for users about the value of water and how to conserve it and rationalizing it through them, and presenting current and future water deficit scenarios for them.

- Involving the private sector in water management.

- Raise the performance and management of workers and the level of services provided to all beneficiaries, especially farmers.

- The importance of reviewing the laws that infringe on the irrigation and drainage networks and concealing penalties, while tightening the government's supervisory role and putting the penalties in place.

- The trend towards increasing the water resource from the source to obtain the maximum benefit.

- Establishing systems for monitoring water pollution cases and for rapid response and setting up accountability mechanisms.

- Obligating farmers to adhere to the agricultural cycle and reducing water-intensive crops.

- Increase the efficiency of water use by using soil conditioners, soil cover, and applying soilless farming systems.

- Raising the efficiency of water, sanitation and water systems, and continuous work on their maintenance and development.

Requirements for achieving efficient planning and management of water resources at the water resource level in light of climate change

- Nile River Water Management

- Establishing a national committee for water in the Nile Basin countries, which reports directly to the prime minister, with a mission to plan, manage and coordinate between governments and the Nile Basin countries.

- Developing political relations among the basin countries, through the African Union and its mechanisms, to address the political and security issues of the basin countries.

- Activating a joint legal and institutional framework among the Nile Basin countries in the field of cooperation to develop the river's resource.

- Dealing in a balanced way with Sudan, its north and south, so as not to create a new water problem for the Egyptian side.

- Benefit from the assets possessed by the Nile Basin region, which outperforms those in the African regions, due to the privileged location or its proximity to the areas of vital interests of the major countries.

- Expanding the areas of confidence-building and moving towards detailing the areas of military cooperation with the Nile Basin countries.

- Stopping untreated industrial drainage, whether direct drainage on the Nile River and its branches, or indirectly on the waterways leading to the Nile River.

- Activating the periodic monitoring efforts to monitor the change in water quality through the Environmental Affairs Agency and the regional branches of the Environmental Affairs Agency, whose results indicate the extent of the change in pollution rates and the extent of its impact from one region to another?

- Follow up plans to reconcile the environmental conditions of industrial establishments that drain the Nile, fresh water and waterways leading to it, with the aim of obliging all establishments to adjust their environmental conditions, whether by implementing new projects to treat industrial drainage or connecting establishments to the sewage networks of cities.

- Rain and flood resource management

- Activating rainwater and torrential harvesting systems, storing water and reusing it when needed.

- Work to increase the quantities of harvested water by selecting the reservoir area where the slope does not exceed $5 \%$ and determining the length of the surface and vegetation cover to work on increasing evaporation.

- Detailed study of the characteristics of rainfalls as they affect the amount of collected water in terms of the amount of rain and the intensity of rain (in millimeters) - where if the intensity of precipitation exceeds the filtration rate, this increases the possibility of water harvesting - and also the distribution of rainfalls.

- Choose the appropriate method for harvesting rainwater according to the characteristics of each region.

- Review all regulations related to rainwater management in order to determine the safety of the systems, ensure their validity, work to maintain them, and work to fulfill the requirements of their success.

- Groundwater resource management

- Taking into account the balance between resource withdrawals and the resource regeneration factor in terms of quantity and quality and their interactions with surface water.

- Maintaining a reasonable balance between the costs and benefits desired from administrative activities and interventions, and therefore must take into account the susceptibility of the hydrogeological system in question to degradation.

- Relying on preventive management methods as they are likely to be more cost-effective.

- The necessity of determining the potential of water available for safe and sustainable exploitation in various uses without deteriorating its quality, and informing those responsible for water management and its users.

- Preparing long and short-term plans for the exploitation of the groundwater resource, with periodic monitoring and review of the behavior of the aquifer to follow up 
the changes that may occur to it in terms of quantity and quality to ensure intervention at appropriate times before the problems escalate.

- The necessity of strict implementation of the laws regulating the exploitation of groundwater resources and their protection from pollution.

- Direct agricultural extension to focus on the basics and rates of using agricultural fertilizers and pesticides, with the aim of reducing the leakage of them into underground reservoirs.

- Maintenance of sanitary drainage networks, while supplying residential areas and villages that lack such networks with suitable networks or analysis tanks with the specifications required reducing human pollution.

- Do not allow the injection of industrial and human pollutants into the underground reservoir while monitoring the ground oil tanks and ensuring their safety from cracks to prevent the leakage of petroleum materials into the groundwater.

- The necessity to follow the ideal design of wells, especially drinking water wells, and to properly choose their location so that they are as far away from the sources of natural pollution as possible, with the upper part of them isolated by cement cleaning to protect them from any direct contamination from the surface.

- The need to intensify public awareness programs through the media and schools on the importance of preserving groundwater sources from pollution, as it is one of the important water sources in meeting the community's needs for drinking and irrigation water.

- Wastewater management

- Classification of wastewater according to the type of treatment, which does not cause waste in the material resources.

- Criminalize the disposal of liquid wastes in rivers, lakes, and seas and imposing heavy penalties on those who do so, and their inclusion in the Water Penal Code.

- Proper planning for reuse of wastewater after treatment to a sufficient degree to prevent harm from its use.

- Development of technology used in water treatment.

- Establishing many measurement stations, such as measuring dissolved oxygen, $\mathrm{pH}$, chloride, fluoride, turbidity, oxidation and reduction status, and solar radiation.

Requirements for achieving efficient management of water resources in various development sectors - in light of climate change.

\section{- Agriculture sector}

- Improving irrigation water efficiency requires making correct decisions related to (type of crop - irrigation times - irrigation methods - water source).

- Choose the types of crops that require less water and provide added value.

- Adjust the time and the amount of water to irrigate crops based on the water content in the root zone of the crops, the amount of water consumed by the crop and the stage of crop development.

- Use appropriate water quality for various types of crops.

- Choosing suitable irrigation methods (surface irrigation - sprinkler irrigation - drip irrigation).

- Proper flatten of the field to allow water to flow at an optimum speed.

- Reliance on alternative water sources for irrigation water, such as harvesting rainwater falling on the field and using treated agricultural drainage water.

- Conducting awareness programs for farmers on water management and conservation methods in agriculture.

- Industry sector

- Re-adjust production plans with a focus on reducing water consumption.

- Introducing more balanced and resource-aware approaches to operations.

- Replacing existing technologies with more effective and efficient technologies.

- Identify leaks and take corrective measures to get rid of them.

- Increasing the effectiveness of heating and cooling needs and certification of central heating and cooling systems.

- Reuse of industrial water, where its cycle is closed.

- The use of treated water for cooling purposes, either directly or after simple treatment.

- Use appropriate water quality for each industry to reduce dependence on drinking water.

- Urban sector

- Charging water service fees on the basis of usage (actual consumption).

- Create an incentive to save water in buildings so that they become aware of their consumption habits.

- Detecting leaks in residential buildings where the number of exits and water users is limited and a center that can be accomplished relatively easily.

- The use of gray water in applications that do not require clean drinking water.

- The use of devices equipped with high standards for water efficiency.

- Dependence on collected rain water to irrigate the buildings' private gardens.

- Introducing the efficiency of water planning and management early in the design and construction stage of buildings. The feasibility of some efficiency measures can be enhanced by reviewing the design components of the water distribution network, water tanks and other water support systems.

\section{CONCLUSION}

The research paper indicates that the phenomenon of climate change has become a reality that must be dealt with seriously, and there is a close relationship between climate change and water resources, and the fact that Egypt is within the Arab region, which suffers from water scarcity and the weakness of mechanisms and ways to make the most of it in various areas of economic, commercial and food life. This critical water situation in the future calls for work to develop medium and long-term policies and plans for planning and managing water resources, and responsibility for their implementation and follow-up is distributed among the state, and community organizations to achieve sustainability, water, and economic and human development. The study used the Delphi method (questionnaire) to monitor and analyze the problems of the water sector in Egypt and the expected gap between the current situation and the desired situation in light 
of climate changes. The study emphasized the necessity of a set of different policies for planning and managing water resources in under the upcoming changes and their importance to the Egyptian society.

\section{REFERENCES}

[1] Ekwueme, B.N., Agunwamba, J.C. (2020). Modeling the influence of meteorological variables on runoff in a tropical watershed. Civil Engineering Journal, 6(12). https://doi.org/10.28991/cej-2020-03091621

[2] Zohdy, H. (1997). A Book of Meteorology and a View of the Future, First Edition, The Science and Life Series. Al-Ahram Foundation for Translation and Publishing.

[3] IPCC. (2007). Fourth assessment report of the intergovernmental panel on climate change. Adaptation and Mitigation Options Contribution of Working Groups I, II and III; Pachauri, R.K and Reisinger, A. (Eds.).

[4] IPCC. (2007). IPCC Fourth Assessment "The Physical Science Basis", Working Group I, 943p.

[5] IPCC. (2007). IPCC Fourth Assessment "The Physical Science Basis", Working Group II, 871p.

[6] IPCC. (year). http: //www.agora-parl.org.

[7] The Egyptian Meteorological Authority (EMA). (2003). http://ema.gov.eg/.

[8] IPCC. (2007). Fourth assessment report of the intergovernmental panel on climate change. Adaptation and Mitigation Options Contribution of Working Groups I, II and III; Pachauri, R.K and Reisinger, A. (Eds.).

[9] Egypt State of the Environment Report. (2017). https://www.eeaa.gov.eg/enus/mediacenter/reports/soereports.aspx.

[10] Gado, T.A., El-Agha, D.E. (2019). Feasibility of rainwater harvesting for sustainable water management in urban areas of Egypt. Environ Sci Pollut Res Int., 27(26): 32304-32317. https://doi.org/10.1007/s11356019-06529-5

[11] Ali, M. (2006). Environment and water. Newspaper, 13584.

[12] Milly, P.C.D., Dunne, K.A., Vecchia, A.V. (2005). Global pattern of trends in streamflow and water availability in a changing climate. Nature Publishing
Group,

438:

$347-350$.

https://doi.org/10.1038/nature04312

[13] Comprehensive Assessment of Water Management in Agriculture. www.iwim.cgiar.org.

[14] Immezeel, W.W., Droogers, P., Terink, W., Hoogeveen, J., Hel-legers, P., Bierkens, M., VanBeek, R, (2011). Middle -East and Northern Africa Water Outlook, Report Future water, 98. https://www.futurewater.eu/projects/mena/.

[15] Doll, P., Florke, M. (2005). Global - scale estimating of diffuse groundwater recharge. Frankfurt Hydrology Paper 03, Institute of Physical Geography, Frankfurt University.

[16] IPCC. (2006). Fourth assessment report of the intergovernmental panel on climate change.

[17] World Bank. (2006).

[18] World Bank, (2017). Making the most of scarcity accountability for better water management in the middle east and north Africa.

[19] Strzpek, K.M., Yates, D.N., Yohe, G., Tol, R.J., Sand Mader, N. (2000). Constructing not implausible "Climate and economic scenarios for Egypt". Integrated Assessment, 2: 139-157. https://doi.org/10.1023/A:1013387619362

[20] Ministry of State for Environmental Affairs. (2008). Environmental affairs agency - Arab Republic of Egypt "Egypt and the issue of climate change: Towards a less carbon-dependent economy" - World Environment Day, Cairo. www.eeaa.gov.eg.

[21] Egyptian Environmental Affairs Agency. (2010). Egypt's Second National Communication: Under the United Nations Framework Convention on Climate Change on Climate Change. https://unfccc.int/resource/docs/natc/egync2.pdf.

[22] British Meteorological Center Hadley. (2001). Climate: Views, Projections and Impacts.

[23] United Nations. (2007).

[24] The Arab Forum for Environment and Development. (1992). The water crisis in the Arab region, the international conference on water and the environment, Irish, Dublin.

[25] Zurek, A., Threaco, D. (2002). Water Resources Planning. Abdel-Mohsen Al-Sheikh, (Eds.) Scientific Publishing House and Press. 